\title{
Raising Productive Efficiency in Industrial Firms (Solutions \& Suggestions for Clothes Industry)
}

\author{
Maha Abdullah Al-Dabbagh ${ }^{1}$, Sara Al Daadi ${ }^{2}$, Ghaida Al Nahari ${ }^{3}$,WeamAl \\ Thagfi $^{4}$
}

Department of Clothing and Textile, Faculty of Home Economics, King AbdulAziz University, Jeddah, Saudi Arabia $a^{1,2,3,4}$

\section{Introduction}

Productive efficiency is the relationship between the inputs of the production process on the one hand and the resultant outputs of that process on the other hand. Productive efficiency means achieving rational production by using the least resources to obtain the best results. The resources mean everything used in the production process, such as work, machinery, raw materials, fuels, etc. In other words, productivity means achieving the best possible production by exploiting the economic fundamentals, leading the best use of all aspects of scientific supervision, time, and money. On the scope of projects, productivity means maximizing the production potentials of the project and its human and material resources. (Jawhar, Ghoneim, \& Heikal, 2010) the optimum level of production is possible if there are savings of scale at different output levels. ${ }^{25}$ That means changes in outputs result in cost-adjusted changes (Evanoff \& Israilevich , 1991). ${ }^{14}$ It also supports the theories of "equity, morale and cohesion," implying that wage adjustment in the workplace and industries may boost productivity. The variation in wages between sectors has contributed positively to the growth of production and productivity(Douglas \& Hakan, 2000). ${ }^{13}$ Therefore, it is necessary to study the factors affecting production efficiency to develop proposed solutions to increase production efficiency in industrial establishments.

\section{Training, Personnel Management, and Productivity}

(Ibrahim, Boerhannoeddin, \& Bakare, 2017)the study aimed to explore the effect of soft skills acquisition and the training methodology \{Time Space\} which is (long-term training, application, and supervision) on the employee's performance. This study was conducted in organizations focusing on the acquisition of "hard" technical skills for staff training and job performance assessment. This study was undertaken to reorient the focus of staff training and development objectives to obtain "soft" skills, which have a significant and enduring impact on employee performance improvement. This study found that 
the combination of long-term training methodology and training of soft skills directly affects the performance of workers since staff who received soft skills training are better in terms of performance after training in the workplace.

The study was conducted in Malaysia. The researchers showed that soft skills training is beneficial to organizations worldwide in soft skills training methodology. ${ }^{24}$

The study of (Almsaeed, 2011)aimed to identify the impact of the strategy of empowerment on the performance of workers in the insurance companies operating in Jordan. The researcher adopted six dimensions of the empowerment strategy, namely: (authorities, knowledge and information, training and development, performance standards: \{appreciation and respect, confidence ). Besides other three dimensions of performance: (performance of work, performance behavior, individual abilities, and capabilities). The study community consists of all employees in (17) Jordanian insurance companies participated in the study. Moreover, the total number of participants is (1424) persons. In this study, the researcher concluded that the commitment to the dimensions of the empowerment strategies mentioned above has a direct impact on the performance of the workers and thus raising the productivity work of the company. ${ }^{9}$

(Jarkas, Bitar, 2001) Construction labor productivity has become such a buzz word and one of the most frequently researched topics. In most countries, labor cost comprises 30 to $50 \%$ of the overall project's cost and thus is regarded as a true reflection of the economic success of the operation. Many challenges are facing the construction industry in the state of Kuwait, but one of the most important is low productivity. The objective of this research, therefore, is to identify and rank the relative importance of factors perceived to affect labor productivity on construction sites in Kuwait. To achieve this objective, a statistically representative sample of contractors was invited to participate in a structured questionnaire survey, comprising 45 productivity factors, classified under the following four primary groups: (1) management; (2) technological; (3) human/labor; and (4) external. Among the factors explored, the subsequent 10 are discerned to be the most significant in their effects on labor productivity: (1) clarity of technical specifications; (2) the extent of variation/change orders during execution; (3) coordination level among design disciplines; (4) lack of labor supervision; (5) proportion of work subcontracted; (6) design complexity level; (7) lack of incentive scheme; (8) lack of construction manager's leadership; (9) stringent inspection by the engineer; and (10) delay in responding to requests for information. The results obtained fill a gap in knowledge of factors affecting labor productivity in Kuwait, which can be used by industry practitioners to develop a broader and deeper perspective of the factors influencing the efficiency of operatives and provide guidance to 
construction managers for efficient utilization of the labor force, hence assist in achieving a reasonable level of competitiveness and cost-effective operation. ${ }^{2}$ The study of ( $\mathrm{Li}$, Chow, \& Lin, 2016)provides industry workers with a better understanding of the effects of high-temperature conditions on labor productivity. The information can help develop plans to prevent heat stress injuries and help improve the safety and comfort of work environments for structural labor. It was measured land temperature data on-site and labor productivity data related to uninterrupted working time, long work time and deceleration time in two construction projects involving 16 workers of reinforcing steel in the summer of 2014 in Beijing, China. The period from 14:00 to 15:00 was identified as the most dangerous for workers throughout the day. The period from 7:00 am to 9:00 pm was set as the least wrong time. The results of the model showed that high-temperature environments reduce labor productivity, with a $0.57 \%$ reduction in direct labor time and a $0.74 \%$ increase in downtime when increased by $1^{\circ} \mathrm{C}$. The workers' experience increased by one year and decreased by $0.72 \%$ when the age of workers increased by one year. The results showed that high-temperature environments impose thermal pressure on the human body and reduce labor productivity in the construction industry. ${ }^{28}$

Work productivity has a significant impact on the time, cost, and quality of the construction project. Since the competitive environment of the construction industry forces the construction companies to increase the production values of workers in order to maintain their positions in the industry. The identification and assessment of factors affecting labor productivity are crucial for industrial practitioners. Many studies have examined these factors and their relationship with labor productivity. In these studies, the factors were categorized under different categories and classified according to their levels of importance; however, in most of these studies. Directors' views were generally taken into consideration while the views of handicraft workers were ignored. In the study ( KAZAZ, ULUBEYL, ACIKARA, \& ER, 2016), factors under the same groups were reassessed from artisans. The results revealed that, although the order of factors remained the same, their levels of importance had changed. ${ }^{3}$

As in (Ranganathan, 2018) the training by constructors with many years' experience is useful in preventing female workers from leaving the job for the first time shortly after they are recruited. Rather than focusing solely on jobspecific skills, the training of experienced trainers includes necessary job readiness skills such as self-presentation, interpersonal communication, separation of work, life, and self-reliance needed to stay at work. It is found randomly that women who worked almost for experienced trainers had a 20 percent greater probability of retaining them after three months. They reported feeling more willing to work than those with less experienced trainers. The 
results indicate that for the majority of workers who are underrepresented and enter the workplace for the first time, training is important to enhance their survival, and for organizations that focus on both the characteristics of those providing that training and its content and have a greater chance of retaining these workers in the long term and increase their efficiency and consequently increase effectiveness and productive efficiency. ${ }^{35}$

In ( Back, 2017)study about the fast fashion industry produced cheaply and in large quantities and environmental damage caused by increased pollution, waste, and mistreatment of workers. The research aims to recommend more sustainable and ethical practices in garment manufacturing. The study concluded that fast fashion is a dangerous trend and encourages overuse and has the impact of abusing workers as well as low wages for performed work. Therefore, it is necessary to limit harmful production practices. Factories should take care of the safety of workers and maintain their rights. It is important to develop international practices that reduce waste of materials, pollution and maintain workers' rights in fast garment factories. ${ }^{1}$

The study of (Singh, 2016) discusses the textile industry in India and its contribution to the growth of the Indian economy and providing work for the rural population and cities in India. However, workers faced some risks in the industry, such as exposure to cotton dust and chemicals and noise problems, etc. Other factors may be responsible for causing hazards in work environment such as improper use of personal protective \{equipment, devices, and machinery\}, unhealthy working environment, poor working conditions, etc. Most workers are illiterate and do not know the preventive measures that must be adopted while doing their jobs. Workers must be aware of the various occupational risks. Here comes the role of the management of the establishment for taking the necessary steps to protect the workers. This shows us the importance of training courses for workers in order to learn how to avoid accidents and risks of work.Moreover, the appropriate environment should be appropriately lit to avoid eye strain and that the seats and tables should be well matched to avoid muscular stress. Machines must be well maintained to reduce noise and risks of non-maintenance. Workers must work with time-shift to avoid been subjected to noise for a long time. Moreover, ventilation should be appropriate in the workplace as well as providing facemasks to reduce exposure to dust and gloves to protect the hand from chemicals. Moreover, to provide trained medical personnel, first aid facilities, and safety equipment such as fire extinguishing and fire alarms to achieve a high level of occupational safety for workers. $^{38}$

The study of industrial security (Mnighed \& Alobi, 2018) is considered as one of the most important topics concerning workers security and safety, and their essential role in increasing the productive efficiency of the working individual 
as well, by providing various conditions and means that ensure the worker's comfort and safety and help them avoid dangers. Also, to improve the health of workers to the maximum possible degree as the findings of the study, such as the development and maintenance of machines to reduce their dangers. Moreover, try to develop preventive means and guidance for employees using them. Also, work to choose the right people in the right position by applying psychological and practical tests in the selection of individuals to fill positions within industrial establishments. Moreover, work to create a psychological work environment to reduce the occurrence of accidents. ${ }^{30}$

Study of (Hamdab, 2017; Hassanein, 2018)discuss the subject of wage systems and their impact on the performance of workers, in terms of motivating workers and paying them for work and to know the relationship between the wage and the level of effort exerted by the workers. It was found that low wages do not encourage the worker to perform high quality because the wage does not commensurate with the effort exerted by the workers. And this also results that workers lack a sense of belonging to their institutions and therefore prefer to work additional jobs to raise their financial income. Also, the preference of workers to work in the private sector to work in the sector Year wage decline. This has also led to an increase in the migration of workers abroad to have better opportunities and higher wages, as well as weak information infrastructure for wages, conflict of labor laws and the wage gap between male and female; all affect the level of performance of workers. ${ }^{20 ; 22}$

In the training of workers, the study of (Roberts, Rogers, Thomas, \& Spitzmueller, 2018)dealt with the subject of training and the amounts spent in training, which may reach millions of dollars, but lost annually due to the lack of workers to apply the content of the training in their work and therefore the enterprises do not benefit from the amounts of training. A significant influence on the application of the training process, therefore, must take into account the personality of the trainee worker where he is a conscience and willing to learn in order to develop his talent. The study proves the results of previous research showing the importance of the training process in industrial facilities to raise quality, the impact of the personal factor in the use of training and access the desired results as well as in the study of (Mnighed \& Alobi, 2018), which mentioned the importance of training programs aimed at training and awareness of workers to work correctly and thus avoid the risks of work. ${ }^{36}$

\section{Production lines to increase production efficiency}

The study of (Jawhar, Ghoneim, \& Heikal, 2010) aims to study the different technical factors that lead to a decrease in the productivity of the garment factories in terms of production plans, work-study, means of handling and latest 
technological equipment within the production lines quality of raw used materials and all the technical aspects related to productivity within garment factories. Also, to establish the scientific bases for improving productivity through analyzing and clarifying available opportunities, developing actionable plans of action, follow-up methods, and future modernization methods.The research found that the factor of time loss inside the garment factories and the weak regulation factor for the places of the functional sections and places of production facilities and the absence of clear criteria for reward and punishment and non-application of the study of movement, which determines the basic movements of each of the production processes, are most factors and reasons for the decline in productivity inside the garment factories. ${ }^{25}$

The study of(Hachicha, Triki, \& Masmoudi, 2017), the design of the production line was developed to obtain a global process for the design of the production line. First, the SADT method was used to ensure the apparent satisfaction of finding the best design. Second, this method was used to build the approaching model and design matrices. Third, this approach has been applied for manufacturing to validate the proposed design process. After that, the initial and accounting lines were designed in the software to determine their performance indicators. The results show that the line obtained by the proposed operation is more secure and balanced than the first line by comparing performance indicators. According to this design method, the number of operators can be improved, cycle time can be reduced, and the assembly line obtained is more balanced than the first line. The proposed design process can be enriched by adding other hypotheses (on maintenance strategies, availability of operators, etc.) or limiting constraints on machine speed, cost of resources, and operator skills. ${ }^{19}$

As in (Nahas, 2017), the serial production line consists of machines of failure, repair, and storing. The objective is to determine the optimal preventive maintenance policy, and the optimal allocation of the temporary storing that will reduce the total cost of the system according to the specified system level. The optimal design problem is formulated as one of the aggregate improvements where the decision changes according to temporary storing levels and times between preventive maintenance. To solve this problem, the serial production line consists of machines with the rate of failure and repair and to make the integrated model of the preventive maintenance plan and temporary store. Numerical results showed that preventive maintenance has a significant impact on the productivity and total cost of the serial production line. ${ }^{31}$

In light of this report (Hudson, Shaaban, \& McNamara, 2015)on the performance of unbalanced non-automatic production lines, simulations of production lines are performed with temporary storing units. Statistical analysis shows that patterns have a significant effect in terms of production rate and 
level of storing. That leads to the conclusion that the study of unbalanced lines that are unreliable does not only need to take into account the breakdown of the production line but must also take into account the location of line failure. The work aims to evaluate the effectiveness of unreliable lines with two or more sources to make the balance, such as the delay in the balance between times of service. These models have been tested by monitoring production lines either through control trials or case studies that allow us to assess whether these thumb rules are effectively transferring the simulation to the real world. Other possibilities are available by extending the single lines simulated here into multiple or merging production lines, with different lines to influence the performance of these more complex configurations. ${ }^{23}$

The allocation problem of temporary storing is an improvement issue that involves determining the number of temporary storing sites required to increase the efficiency of the production line. (Kose \& Kilincci, 2015) suggests improving different techniques to solve the problem for different types of production system configurations in this study. The study proposes to improve simulation based on mixed approaches to determine the required sizes in open serial production lines to increase the average rate of the production. Separate models use to obtain the average line production rate. The performance of the proposed technique and the force of various configurations of serial production lines are assessed. The promising results show the effectiveness of the proposed hybrid technique to the allocation problem of temporary storing in open serial lines. ${ }^{27}$

\section{Techniques used to increase productivity efficiency}

(Abdulmalek \& Rajgopal, 2007)the study aimed at applying the Lean Production System to a factory using the Stream Value Mapping Tool (SVM), an easy manufacturing tool, which is a method of presenting a picture map of the production process (Materials, processes and information) from the raw materials needed for the production process to the goods or services produced to the end consumer. The value flow plan is all activities whether resulting in value-added or non-value added to increase productivity, minimize waste and eliminate non-value activities through a pre and post-production model in the factory.

The researcher concluded that the simulation process explained in detail that the proposed system increases productivity and reduces the time and reduces the waste rate in the company. The researcher advises applying simulation systems for companies in case they are not sure of the success of any new system. ${ }^{4}$

(Alshenawi, 2016) the research aims to identify the application of the wastefree production system by identifying all aspects of waste and improvidence in 
the industrial organizations and supporting the strategies of continuous improvement and enhancing in order to achieve competitive advantage. This objective is achieved through studying some advanced administrative and production systems, that facilitate the production free of losses system to achieve its objectives. Moreover, the most important of that is reducing waiting times and increase the level of productivity.

The research concludes that:

1. The factory exceeded the first level of (preparation of the production process of production free of losses system) and second level of (start the operation of the production system free of waste).

The plant is currently between the third level of (inclusion in the production process) and the fourth level of (continuity in the production process).

3 . The plant is still relatively far from the fifth level of (focus on continuous development).

4. The factory level is on Medium-High (MH) and hence the high application of the loss-free production system within the factory. ${ }^{10}$

Since radio frequency identification technology usage is increasing, applications in this area have a rising trend day by day. However, successful studies related to radio frequency identification implementation, which combine many different areas, are not sufficient enough. Studies have mostly emphasized theoretical approaches rather than being practical studies. In this study, a roadmap for radio frequency identification design, configuration, and deployment is presented in order to design an integrated approach as pointed out in the literature and previous radio frequency identification projects. Additionally, an application is performed for validation and reinforcing of the understanding of the proposed radio frequency identification implementation roadmap; an architectural framework and economic feasibility are also discussed. The most striking result from the case study is that a radio frequency identification application could be successfully implemented to support the tracking and tracing of work in process in denim production processes, an area in which studies about radio frequency identification applications have not been done. Besides this, redundant inventory and production costs, unnecessary labor costs caused by inefficient production activities, inaccuracies of records, incorrect order deliveries and penalty costs incurred by customers are significantly reduced, which provides invaluable advantages in the real-life competition of the denim product industry. Moreover, that has been applied in the study of (Choi , Yeung, Cheng, \& Yue, 2018)which showed the good performance of technology of REID to increase the total manufacture capacity and enhance profit. ${ }^{11}$

(Hassan, Elgamal, \& Abdelaziz, 2019) aimed at understanding the effect of the implementation of the policy of the fifth visual management in the garment 
industry. The main idea is that a clean and organized workplace contributes to saving time and effort. It also reduces costs and increases the production rate. Where the senior management is committed to applying new policies and spreading awareness among all employees in the plant regarding the (5S) program (sort, set, sweep, standardize and sustain) and it was found that the work environment and factory arrangement have a significant impact on worker productivity, mastery, and love of work. The facility received several benefits, including the improvement of the psychology of workers during work, and the reduction of work accidents due to the arrangement of tools and standardization of working methods - less effort and time spent to work and also increased labor productivity. As a result of the cleanliness of the facility, cleaning expenses have been reduced. ${ }^{21}$

In (Cruz , Broega, \& Amorim, 2016; Tan, Ayhan, \& Baydaş, 2016)sustainability and cleaner production conditions were analyzed in light of the recent changes taking place in the world. With increasing environmental and economic concerns and the necessity to apply sustainability requirements in production processes. The study found that the primary sources of environmental problems in the clothing and textile sector occur due to water consumption, solid and liquid waste production, dyes, and solvents. ${ }^{12}$ According to the study (Singh, 2016), companies must apply clean production conditions and give the expected increase in world textile production. It also supports and encourages companies in the field of cleaner production, to the usefulness of the company and the community and the environment around them and how can pursuing cleaner production will help enterprises to obtain the ISO quality certificate and thus increase the competitiveness of company against other companies in this sector. Through the recycling and management of waste in factories through the establishment of a waste management department by classifying and regulating it to be used as raw material for new products instead of burning or dumping them, this supports sustainability for present and future generations. Moreover, there should be cooperation among countries and to increase public awareness. ${ }^{38}$

In the study (Ahmed \& Salama, 2017), the issue of management in industrial establishments and the efforts of modern institutions to cope with changes in the surrounding environment were addressed. The process of engineering processes was highlighted. It is meant to redesign administrative processes to achieve substantial improvements radically, or another definition is to start over from scratch and not to repair and restore the status quo or to make simple changes leaving the infrastructure as it was. The application of administrative management benefits by combining the interdisciplinary work in one place to save time and shift jobs from simple tasks to intricate work, and also to rely on education to increase skills rather than training. It is more targeted at enterprises 
with a deteriorating situation, which face higher operating costs or lower services to the level that drives their customers to complain and grumble away from the competition. ${ }^{6}$

The study (Abdulrahman, 2016)dealt with the system of production on time, which is one of the modern systems that serve organizations of all kinds to assist them to achieve economic savings and competitive advantages. The JIT system or the production system on time aims to bring raw materials only when production is needed, to reduce the cost of keeping storage and to reduce waste in manufacturing while ensuring quality improvement. The system works to eliminate waste and focus on products as required quantity and quality. Delivery of materials and time of completion of these products and delivery to the customer quickly in a manner that achieves the competitive advantage of the facility. The study concluded that the application of the system provides the quality of the facility and also reduces the production time and time of preparation and readying and access to the minimum storage. ${ }^{5}$

(Khalil \& Obaid, 2018) studies the impact of effective industrialization in enhancing the competitiveness of the companies, and productive manufacturing is meant to refer to rapidly change product through the use of the elasticity of production and information technology. It is a new system used to meet the challenges of competition and rapid response to customer requirements at any time. Thus, improving the productive efficiency of the enterprise, achieving competitive excellence and making the organization viable in the long term and increasing its profits. It was concluded that organizations could apply the effective manufacturing system through the following components (IT, smart workers, united partners). The analysis showed that competitiveness contributes to improving the performance of the companies through the ability and adjust different market factors and variables, as well as its ability to provide high quality, low-cost and timely delivery products, thus achieving a competitive position. Information technology has a clear and influential role in enhancing the competitiveness of the company by connecting it to the following dimensions (quality, innovation, cost, flexibility, delivery), which demonstrates the contribution of information technology to improving the performance of companies. $^{26}$

\section{Conclusion}

Raising production efficiency is achieved through more than one strategy. The increase in output, the reduction of inputs, fixed capital, raw materials, labor, transport expenses and productivity may also be achieved through the use of modern manufacturing techniques. 
Factors influencing production efficiency are the scientific methods of management and management tools for decision making, as well as the efficiency and management skills of the management practice of its functions of planning, organization, direction and control.

Despite the importance of other factors in influencing productivity, administrative factors are considered to be the most important factors influencing production efficiency besides human factors, the ability to work includes education and skills, the desire to work. Production is affected by the needs of individuals, the physical working conditions and meetings. Training affects and assists to carry out tasks easily and reduce the commission of errors in the work contribute to increase productivity and development of technical inputs in the development of machines and equipment and technical systems. Collective technology through the division and compilation of recurrent or similar problems, which helps to avoid duplication of efforts to solve problems and save time, production on time, cost control and optimal use of available resources and material incentives and participation in decisions to develop work.

The efficiency of production indirectly increases growth and stimulates productivity in developing countries. When the production process is carried out in a timely manner. It will improve storage operations. The entry of raw materials used in the manufacturing process timely will reduce the need for storage, which in turn increases productivity and reduces costs.

In conclusion, this review of the various researches and studies in the field of industry and management of industrial establishments has presented several expectations and proposals for industrial establishments and other uses, from the management of enterprises and how to increase productivity, and plan factories. Also, in the field of workers and how to achieve the highest utilization of labor while maintaining the rights and full care of workers.

There are many studies and efforts done to reach the maximum amount of information and results that contribute to the upgrading and development of industrial facilities and achieve the highest productivity.

\section{References}

1. Back, J. (2017). Sustainable and Ethical Practices for the Fast Fashion Industry. UEP Student Scholarship.

2. Jarkas, A. M., \& Bitar, C. G. (2011). Factors Affecting Construction Labor Productivity in Kuwait. Journal of Construction Engineering and Management, 138(7), 811-820. 
3. KAZAZ, A., ULUBEYL, S., ACIKARA, T., \& ER, B. (2016). FACTORS AFFECTING LABOR PRODUCTIVITY: PERSPECTIVES OF CRAFT WORKERS. Creative Construction Conference, 164, pp. 28-34.

4. Abdulmalek, F. A., \& Rajgopal, J. (2007). Analyzing the benefits of lean manufacturing and value stream mapping via simulation: A process sector case study. International Journal of Production Economics, 107, 223-236.

5. Abdulrahman, M. \&. (2016). The Possibility of Establishing the Requirements of the Production Just in Time System JIT: An exploratory study of the opinions of managers in the mineral water plants in Duhok Governorate. Arab Administrative Development Organization, 226-227.

6. Ahmed, A., \& Salama, W. (2017). Reengineering the Human Resources (Handara) and its Role in Enhancing the Competitiveness of Hotel establishments. Applied Study on some of the Egyptian Five Star Hotels. Journal of Association of Arab Universities for Tour, 14(1), 149164.

7. Al-Jamal , J. (2017). Printed Ladies Cloaks between Culture Identity and Technological Progress. Journal Of Architecture And Art And Humanistic Science, 5, 1-25.

8. Al-Khwaldeh, A. (2018). The Impact of Soft Total Quality Management Practices on Product Innovation in the Industrial Companies Operating in King Abdullah II Industrial Estate. Department Of Business Administration - Al Al-Bayt University, 94.

9. Almsaeed, M. (2011). The effect of empowerment strategy on employee's performance at insurance companies operating in Jordan.

10. Alshenawi, M. (2016). Lean Production Application Requirements for Industrial Organizations: An Empirical Study on Kapci Coatings. Journal Of Financial And Commercial Research, 2, 238-263.

11. Choi , T. M., Yeung, W. K., Cheng, E., \& Yue, X. (2018). Optimal Scheduling, Coordination, and the Value of RFID Technology in Garment Manufacturing Supply Chains. IEEE Transactions on Engineering Managemnt, 65(1), 72-84.

12. Cruz , H., Broega, A. C., \& Amorim, M. (2016). Sustainability in Fashion: A Study of Clean Waste Management within a Clothing Company. University of Minho, Portugal.

13. Douglas , H., \& Hakan, L. (2000). Wage Dispersion and Productive Efficiency: Evidence for Sweden. Journal of Labor Economics, 18(4), 755-782. 
14. Evanoff, D. D., \& Israilevich , P. (1991). Productive Efficiency in Banking. Economic Perspectives, 15(4), 11-32.

15. Fohr, J. (2015). Heat and Humidity Transfer in Clothing.

16. Gao, C., \& Kuah-Pearce, K. (2015). The Garment Industry in South China. The Garment Industry Between Local Configurations and Global Flows, 3, 25-32.

17. Giannakis, M. (2011). Conceptualizing and managing service supply chains. The Service Industries Journal, 31(11), 1809-1823.

18. Gulhane, S., \& Turukmane, R. (2017). Effect of Make in India on Textile Sector. Journal of Textile Engineering \& Fashion Technology, 3(1).

19. Hachicha, W., Triki, H., \& Masmoudi, F. (2017). Manufacturing system design based on axiomatic design: Case of assembly line. Journal of Industrial Engineering and Management, 10(1), 111-139.

20. Hamdab, S. (2017). Wage systems and their impact on the performance of workers in public sector institutions in Sudan: Case Study of the Ministry of Finance, Economy and Manpower. University Of AlJazirah.

21. Hassan, N., Elgamal , G., \& Abdelaziz, I. (2019). The Impact of Applying Visual Management Policies and 5S's on Improving Productivity within Garment Factories. Journal Of Architecture And Arts, 13.

22. Hassanein, H. (2018). Targeting wages as a mechanism to increase labor productivity and reduce unemployment in Egypt. Journal of Development and Economic Policies, 37.

23. Hudson, S., Shaaban, S., \& McNamara, T. (2015). The performance of unpaced production lines with unbalanced mean operation times and unreliability patterns. Journal of Manufacturing Systems, 37, 164-172.

24. Ibrahim, R., Boerhannoeddin, A., \& Bakare, K. K. (2017). he effect of soft skills and training methodology on employee performance. European Journal of Training and Development, 41(4), 388-406.

25. Jawhar, E., Ghoneim, A., \& Heikal, H. (2010). Studying the Elements Affecting Productivity Diminution in Ready-Made Garments Factories. Journal of Science and Arts, 23(3).

26. Khalil, A., \& Obaid, M. (2018). The Effect of Effective Manufacturing Components in Enhancing Competitiveness of Business Organizations An Analytical Exploratory Study in the Middle Refineries Company (Al Doura Refinery). Journal of Administration and Economics, 116, 156178. 
27. Kose, S. Y., \& Kilincci, O. (2015). Hybrid approach for buffer allocation in open serial production lines. Computers and Operations Research, 60(C), 67-78.

28. Li, X., Chow, K. H., \& Lin, Y. (2016). Evaluating the impacts of hightemperature outdoor working environments on construction labor productivity in China: A case study of rebar workers. Building and Enviroment, 95, 42-52.

29. LORENZ, K. (2009). Top 10 Soft Skills for Job Hunters. Retrieved from http://jobs.aol.com.

30. Mnighed, A., \& Alobi, Y. (2018). The components of industrial security and its role in reducing accidents. Journal of Law and Human Sciences, Economic Studies, 16(33), 397-404.

31. Nahas, N. (2017). Buffer allocation and preventive maintenance optimization in unreliable production lines. Journal of Intelligent Manufacturing, 28(1), 85-93.

32. Narayan, P. (2001). Fiji's Garment Industry: an Economic Analysis. Journal of Economic and Social Policy, 6(1).

33. Oner, M., Ustundag, A., \& Budak, A. (2017). An RFID-based tracking system for denim production processes. The International Journal of Advanced Manufacturing Technology, 90(1-4), 591-604.

34. Pham, Q., \& Hara, Y. (2011). KM Approach for Improving the Labor Productivity of Vietnamese Enterprise. International Journal of Knowledge Management, 7(3), 27-42.

35. Ranganathan, A. (2018). Train Them to Retain Them: Work-Readiness and Retention of First-Time Women Workers in India. Administrative Science Quarterly, 63(4), 879-909.

36. Roberts, Z., Rogers, A., Thomas, C. L., \& Spitzmueller, C. (2018). Effects of proactive personality and conscientiousness on training motivation. International Journal of Training and Development, 22(2).

37. San, G., Huang, T., \& Huang, L. (2008). Does labour quality matter on productivity growth? The case of the Taiwanese manufacturing industry. . Total Quality Management \& Business Excellence, 19(10), 1043-1053.

38. Singh, N. (2016). Safety and health issues in workers in clothing and textile industries. International Journal of Home Science, 2(3). 


\section{Abstract \\ Raising Productive Efficiency in Industrial Firms (Solutions \& Suggestions for Clothes Industry)}

This paper is a review of several analytical studies concerned with manufacturing technology and the flow of materials within the manufacture until the end product, and how to raise productivity which means achieving the best possible production by exploiting the economic fundamentals, leading the best use of all aspects of scientific supervision, time, money and employees

On the scope of projects, productivity means maximizing the production potentials of the project and its human and material resources. (Jawhar, Ghoneim, \& Heikal, 2010)using different kinds of new technology and other systems that have been conducted in these studies, for example, lean production system, just in time production method, Kanban system, value stream mapping, total productivity maintenance, softskills, five visual management policy $(5 \mathrm{~S}){ }^{25}$ In conclusion, this review of the various researches and studies in the field of industry and management of industrial establishments has presented several expectations and proposals for industrial establishments and other uses, from the management of enterprises and how to increase productivity, and plant factories.

\section{Keywords}

Textile industry, productive efficiency, labor productivity, long-term training.

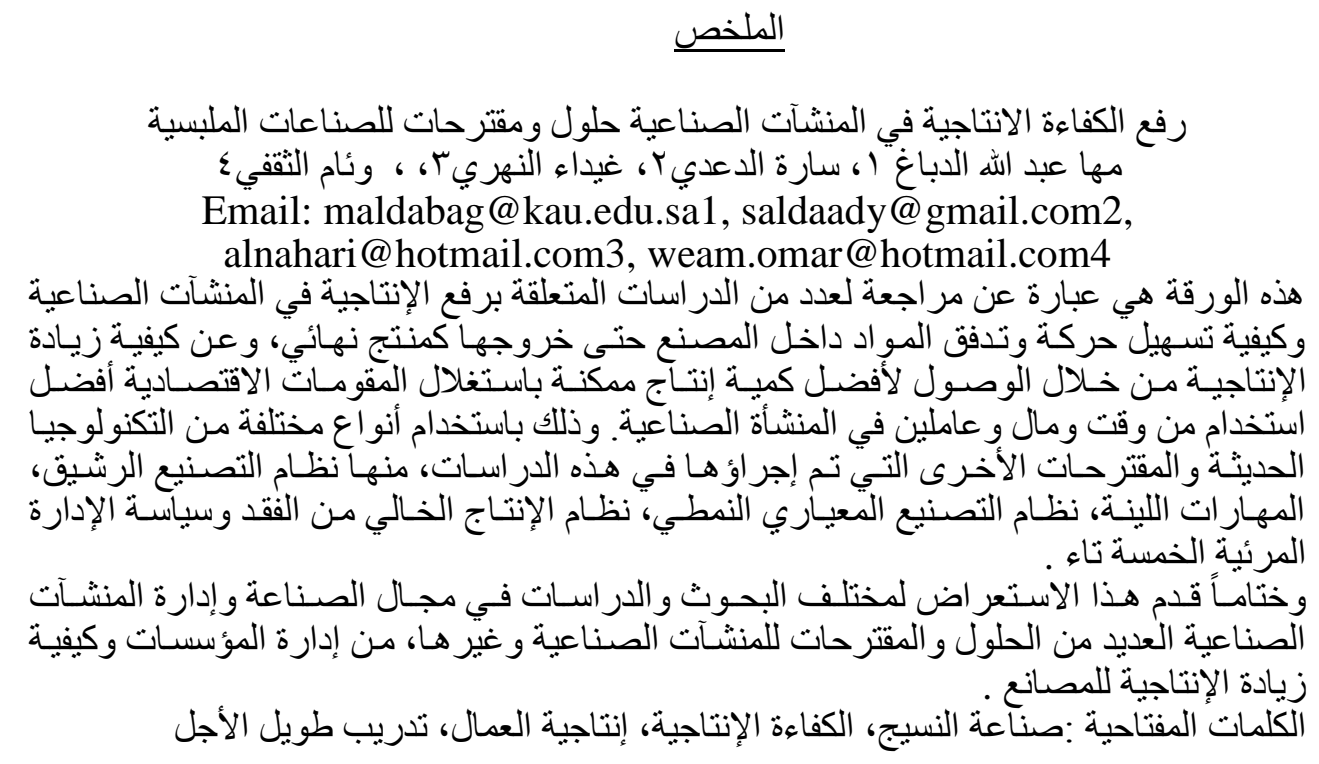

